\title{
O ensino de Matemática por meio da contextualização e da pesquisa
}

\author{
Sandryne Maria de Campos Tiesen \\ Rafaele Rodrigues de Araujo
}

\begin{abstract}
Resumo: 0 presente artigo teve por objetivo descrever e analisar a potencialidade de uma atividade didática contextualizada para o ensino de Matemática com estudantes do primeiro ano do Ensino Médio. Para isso, utilizamos a metodologia da pesquisa-ação para realizar a investigação sobre o uso de celular em sala de aula no ensino de Matemática. $\mathrm{Na}$ análise dos resultados emergiram duas categorias: compreensões dos estudantes em Matemática a partir de questões cotidianas, e a pesquisa como potencializadora do ensino e da aprendizagem em Matemática. A partir da discussão realizada nessas categorias, argumentamos que, ao realizar uma prática contextualizada e investigativa no ensino de conceitos matemáticos, potencializamos o processo de formação de sujeitos conscientes e críticos.
\end{abstract}

Palavras-chave: Contextualização. Ensino de Matemática. Pesquisa.

\section{Mathematics teaching through contextualization and research}

Abstract: This work aimed to describe and analyze the potential of a contextualized didactic activity for the teaching of Mathematics with students of the first year of High School. For that, we used the action research methodology to investigate an activity on the use of cell phones in the classroom in the teaching of Mathematics. In the analysis of the results, two categories emerged: students' understandings in Mathematics from everyday questions, and research as a potential for teaching and learning in Mathematics. From the discussion held in these categories, we argue that by carrying out a contextualized and investigative practice in the teaching of mathematical concepts, we enhance the process of forming conscious and critical subjects.

Keywords: Contextualization. Math Teaching. Research.

\section{Enseñanza de las Matemáticas a través de la contextualización y la investigación}

Resumen: Este trabajo tuvo como objetivo describir y analizar el potencial de una actividad didáctica contextualizada para la enseñanza de las Matemáticas con alumnos de primer año de Bachillerato. Para ello, utilizamos la metodología de investigación-acción para investigar una actividad sobre el uso de teléfonos móviles en el aula de la enseñanza de las Matemáticas. En el análisis de los resultados, surgieron dos categorías: la comprensión de los estudiantes en matemáticas a partir de preguntas cotidianas, y la investigación como potencial para la enseñanza y el aprendizaje de las matemáticas.

Palabras clave: Contextualización. Enseñanza de las Matemáticas. Investigación.
Sandryne Maria de Campos Tiesen Mestranda em Engenharia de Processos Tecnologias pela Universidade de Caxias do Sul (UCS). Rio Grande do Sul, Brasil.

(iD) orcid.org/0000-0001-9682-9400

$\triangle$ sandrynetiesen@outlook.com

Rafaele Rodrigues de Araujo Doutora em Educação em Ciências. Professora do Programa de Pós-Graduação em Educação em Ciências Universidade Federal do Rio Grande (FURG). Rio Grande do Sul, Brasil. D) orcid.org/0000-0003-4901-6196 $₫$ araujo.r.rafa@gmail.com

Recebido em 12/08/2020 Aceito em 21/09/2020 Publicado em 16/11/2020 


\section{Introdução}

As diversas temáticas que fazem parte da área da Educação sofrem mudanças a todo tempo, muitas dessas relacionadas a forma de ensinar e de aprender. Vinculamos esse fato principalmente aos métodos tradicionais e atuais de ensino, sendo que a cada dia tem-se novas perspectivas sobre essas questões. Dessa forma, torna-se emergente discussões que envolvam a prática pedagógica dos professores.

O método tradicional de ensino se destaca em frente a outras metodologias, pois é a forma mais utilizada dentro das salas de aula, que nos remete à uma questão cultural. Na forma tradicional de ensinar, algumas características se ressaltam, como a prioridade de finalizar conteúdos em tempos determinados, independentemente de o estudante ter compreendido ou não. A cópia repetitiva, seja na forma de exercícios e a pouca prática fazem parte desse método.

Consideramos por metodologia de ensino tradicional aquela em que o estudante é passivo em sala de aula e o professor o detentor do conhecimento. De acordo com Becker (1995), um modelo pedagógico que se enquadra dentro da metodologia tradicional de ensino e de aprendizagem é intitulada de empirismo. Nesse modelo, o professor não aprende com seu aluno e esse é incapaz de ensinar algo.

Dessa forma, compreendemos que o ensino vai além da pura transmissão ou da emissão do papel de professor, mas existe uma necessidade de repensarmos o ensino enquanto construção do conhecimento e com o uso de metodologias diferenciadas. Com isso, olhamos para o modelo pedagógico construtivista de Becker (1995), o qual o professor escolhe o material para ser levado para sala de aula e solicita para que seus alunos o explorem, tornando-os autores desse processo de ensino e de aprendizagem, acreditando, assim, que o aluno possa assimilar e construir de forma significativa o conteúdo.

Em relação as metodologias de ensino e de aprendizagem em Matemática, percebemos que são diversas as formas que podemos trabalhar com nossos estudantes. No entanto, existe um abismo na aprendizagem de Matemática, devido ser uma ciência exata conhecida por seus obstáculos, que envolve a abstração e o raciocínio lógico. Nessa perspectiva, por diversas vezes o motivo do estudante não se destacar na disciplina é a falta de contextualização. Várias pesquisas nos mostram a importância de contextualizar o conteúdo de Matemática para potencializar 0 aprendizado desses conceitos, que muitas vezes são abstratos e não permitem ao estudante compreender que os conteúdos podem estar relacionados a fatos cotidianos (NOGUEIRA NETO, 
2019; SOUZA, 2019).

A Matemática, em muitos dos casos, é temida entre estudantes, devido existir um sentimento de incapacidade de compreendê-la. $O$ aprendizado nessa área exige criatividade, raciocínio e desenvolvimento de uma linguagem adequada ao seu entendimento. É pertinente pensar que a linguagem matemática está associada ao conteúdo e à forma que é expressa. $\mathrm{A}$ construção do pensamento matemático se inicia quando o estudante é capaz de identificar um significado para o que é proposto pelo professor (LESSA e FALCÃO, 2005). Em vista disso, percebe-se uma necessidade de tornar o aprendizado em Matemática prazeroso, por meio de algo que seja significativo e atrativo na vida do estudante. De acordo com Bueno, Alencar e Millones (2017), um bom método para se obter significado na aprendizagem é desafiar os alunos, propor aos mesmos situações-problema que os estimulem a resolver. Dessa forma, além de ensinar os conceitos matemáticos de maneira diferenciada, os estudantes se sentirão inclusos nesse processo.

No entanto, tornar o ensino atrativo é um desafio para o professor, mas importante para os estudantes, visto que para tornar a aprendizagem dinâmica, é preciso fornecer uma mudança significativa nos processos de ensino e de aprendizagem. Por diversas vezes, os estudantes não compreendem os conceitos matemáticos da maneira tradicional, necessitando de outros métodos para 0 entendimento.

Com isso, refletindo sobre a dificuldade em tornar o aprendizado em Matemática atrativo, ressaltamos que o uso de instrumentos diferenciados no ensino se torna fundamental, pois dependendo da utilização podem despertar o interesse e auxiliar nos processos de ensino e de aprendizagem. Ensinar é um ato que exige um processo de aperfeiçoamento, pois mostra ao estudante que existe um significado do aprendizado em sua vida.

De acordo com Maioli (2012), a contextualização no ensino é feita de forma com que 0 estudante vincule 0 conhecimento à sua origem. A referida autora explicita que a contextualização precisa ser proposta ao ensino, afirmando que aprender é muito mais do que memorizar 0 conteúdo, e que a presença de tecnologias se torna essencial.

Nessa perspectiva, emerge a necessidade da inserção de outras metodologias para 0 ensino dos conceitos matemáticos, visto que percebemos a contextualização como uma forma de tornar esse aprendizado significativo. Com isso, trazemos como temática emergente para a sala de aula de Matemática, o uso do aparelho celular, o qual possui destaque na vida de todos, seja 
em qualquer ambiente, proporcionando meios de comunicação, conhecimentos e interações.

Com as questões apresentadas, e a inserção do celular em nossas vidas, assim como suas vantagens, buscamos relacionar o ensino de Matemática por meio da utilização do celular. Dessa forma, o objetivo dessa pesquisa é descrever e analisar a potencialidade de uma atividade didática contextualizada para o ensino de funções com estudantes do Ensino Médio. Nesse sentido, nas próximas seções aprofundaremos teoricamente essa temática e explicitaremos essas relações por meio de uma atividade realizada em sala de aula.

\section{Contextualização no ensino de Matemática}

Iniciamos a discussão teórica significando nossas compreensões sobre contextualização, a qual é entendida como sendo um princípio pedagógico que tem como objetivo visar a melhoria da aprendizagem dos alunos, envolvendo o conhecimento e sua relação com a vida do estudante. Para tanto, construir conhecimentos não é uma ação simples, pois o professor precisa instigar o estudante, de modo a apresentar um propósito para o que está sendo abordado naquele momento e fazendo-o, dessa forma, compreender o motivo do aprendizado.

Sabemos que somente o domínio do conteúdo não resolve todas as questões do processo de ensinar e aprender, visto que para contextualizar o professor necessita relacionar 0 assunto com a realidade, para que assim possa dar sentido à formação de um novo conceito (REIS e NEHRING, 2017). De acordo com Tufano (2002), a contextualização é algo particular, que depende do modo que cada um compreende os fatos e fenômenos. O referido autor afirma que a contextualização não pode ser titulada como um processo rotineiro, pois teríamos resultados indiferentes, que pouco acrescentariam no desenvolvimento do estudante, requerendo diversidade.

A necessidade por metodologias diferenciadas no ensino, se refere aos professores que não inovam, muitas vezes, por entender que somente sua experiência pode dar subsídios ao ensino e à aprendizagem. Sabemos que os estudantes não aprendem da mesma maneira e no mesmo tempo, e que por diversas vezes estudantes de mesmo nível da Educação Básica, estão em estágios diferentes. Sendo assim, a busca por mudanças no ensino se torna cada vez mais essencial, sugerindo que a prática pedagógica dos professores necessita ser aperfeiçoada. Desse modo, o professor pode ter um olhar diferente para cada estudante e (re)pensar suas estratégias de ensino, adotando atividades alternativas e a utilização de instrumentos que ajudem a assimilar 
o conteúdo (ALBINO, 2015).

Uma proposta de ensino que tenha por objetivo preencher lacunas no conhecimento do estudante e que o estimule a ir em busca de respostas, de modo que estabeleça significado no processo de aprendizagem, é atualmente o que entendemos como forma de inovação no ensino. Desde os Parâmetros Curriculares Nacionais (PCN) temos um destaque a interdisciplinaridade e a contextualização no ensino (BRASIL, 1998), e de acordo com a Base Nacional Comum Curricular (BNCC) a contextualização é determinante em todas as áreas, pois é dessa forma que se prepara estudantes com iniciativa, com bons argumentos e julgamentos (BRASIL, 2017). Além da contextualização, o documento da BNCC salienta a importância da clareza, relevância e pertinência ao se ensinar Matemática. Dando ênfase ao ensino de Funções, foco deste estudo, na BNCC é abordado como um dos principais conteúdos do Ensino Médio, pois possibilita um progresso na capacidade de pensar do estudante e de determinar uma relação entre grandezas e variáveis (PINTO, 2017).

Para possibilitar a inserção da contextualização no ensino da Matemática, deve-se priorizar a elaboração de atividades que mostrem aos alunos a relação com a sua realidade. Além disso, essa forma de trabalhar os conceitos mostra-se importante para o aluno, devido propiciar 0 contato com problemas que envolvam contextos sociais e científicos, de forma a levantar hipóteses de resolução, fazendo com que o mesmo não tenha a resposta de imediato.

Nessa perspectiva, ressaltamos que a contextualização no ensino, seja em qualquer área do conhecimento, propicia ao estudante a junção entre a aprendizagem e a realidade. No entanto, para complementar essa metodologia de ensino, compreendemos que para contextualizar necessitamos também analisar a forma com que esse estudante aprende, de modo a considerar seus conhecimentos prévios nesse movimento de mudança conceitual para o conhecimento científico. Assim, na próxima seção trazemos uma breve discussão sobre a aprendizagem significativa de Ausubel e de como essa pode contribuir no ensino de Matemática.

\section{Aprendizagem Significativa}

A aprendizagem significativa é uma teoria que disserta que a aprendizagem é potencializada quando ocorre a interação do novo conhecimento com algo já aprendido, como forma de ampliação desses conhecimentos. Dessa forma, é necessário levar em consideração o conhecimento prévio do sujeito sobre a informação trabalhada. 
Para se construir novas aprendizagens, é necessário além do conhecimento prévio, também dar significado para o que é aprendido. Para David Ausubel, a aprendizagem significativa está associada à uma estrutura cognitiva, para a qual há uma distribuição ordenada de acordo com a importância de cada conhecimento do indivíduo.

Existem condições que devem ser conhecidas para a aprendizagem ser considerada como significativa. 0 aluno deve ter interesse em relacionar o que foi aprendido à sua estrutura cognitiva e o material proposto pelo professor deve ser teoricamente capaz de possibilitar a atribuição de significado. Quando os materiais propostos pelo professor são incapazes de proporcionar algum significado ao estudante, ou quando esse apenas memoriza o que the é proposto, ocorre somente a fixação do conteúdo. Dessa forma, a aprendizagem se torna mecânica, em que o propósito é economizar tempo e esforço. A aprendizagem significativa que buscamos é quando o estudante não memoriza o novo assunto, mas que assimila 0 assunto com conceitos relevantes pré-existentes (PONTES NETO, 2006).

A educação precisa de reformas, para que o estudante não somente aprenda, mas saiba aprender a aprender, para esse fim, primeiramente deve-se notar o desenvolvimento do aluno, pois a realização educativa está inteiramente ligada ao grau de aprendizagem que esses sujeitos são capazes de desenvolver. De acordo com Martins (2003), aprender a aprender consiste em desenvolver a aprendizagem de forma com que após o período escolar, o conhecimento continue a evoluir. Com isso, é posto dois posicionamentos de valor sobre o lema "aprender a aprender", sendo que o primeiro se baseia na transmissão do conhecimento, ser capaz de transmitir o que se foi aprendido, e o segundo posicionamento fundamenta a importância da construção de um conhecimento contínuo.

Toda atividade necessita de um ponto de partida, chamado de conhecimento prévio, a qual utiliza o que se foi construído anteriormente como âncora na construção de novos conhecimentos. Com isso, a aprendizagem significativa está relativamente associada às atividades propostas em sala de aula. Desse modo, é concedido a continuidade das aprendizagens passadas e a partir disso acontece a mudança conceitual, de forma com que 0 estudante entenda que tudo que é aprendido, é significativo nesse processo de ensino e aprendizagem, e que possa progredir diante um processo de educação (MAIOLI, 2012; PELIZZARI et al., 2002).

O conhecimento pode ser entendido como uma rede de significações, de forma que 
devemos considerar os conhecimentos construídos anteriormente, para que se possa dar continuidade ao processo de ensino e aprendizagem. Isto está fortemente relacionado à significação conceitual, em que o estudante percebe os motivos dos conceitos que foram ensinados.

O estudante aprende quando assimila o conteúdo com a realidade, de forma a identificar uma relevância no que se aprende, então é possível destacar que a significação consiste em estabelecer o valor da aprendizagem e a relacionar com o cotidiano do aluno. A Matemática, em alguns momentos, desempenha um papel instrumental a ser capaz de se relacionar com nosso cotidiano, ajuda na construção de raciocínio e relacionada com a vida se torna uma ferramenta essencial. 0 ensino da Matemática envolve conhecimentos práticos, não somente teóricos, de maneira que o aluno consiga sentir a necessidade do saber, para que relacione com seu desenvolvimento na vida contemporânea (REIS e NEHRING, 2017).

Construir o conhecimento com o estudante de forma com que se saiba a origem desse conhecimento fortalece a significação; é interessante destacar a origem da Matemática e que, por ser uma ciência universal, se aplica em diversas culturas. Ao ensinarmos, seja qualquer área do conhecimento, é conveniente proporcionar a busca pela solução de problemas, de forma com que o estudante se instigue a resolver. Além disso, vale destacar que da mesma maneira que buscamos que 0 ensino e a aprendizagem sejam significativos para o estudante, deverá ser significativo para o professor (SOUZA, 2009).

É somente com o tempo que os significados vão se estabelecer, a interpretação de um novo conhecimento não acontece de forma instantânea, requer que se atribuía um valor para 0 que se aprende. Dessa forma, percebemos que há diversas possibilidades de realizar novas aprendizagens e relacioná-las com a realidade. A aprendizagem significativa é um princípio necessário na construção do conhecimento do estudante, e se torna indispensável para 0 professor, para que assim existam possibilidade da inovação na educação.

Nesse sentido, nas próximas seções apresentaremos um material desenvolvido que levou em considerações as discussões teóricas apresentadas. Com isso, apresentaremos esse material e analisaremos seu potencial como uma atividade didática contextualizada para o ensino de funções com estudantes do Ensino Médio. 


\section{Percurso metodológico: Pesquisa-ação}

A investigação realizada possui um caráter qualitativo, pois apresenta uma natureza exploratória, que busca estimular o pensamento de modo recursivo. Nesse sentido, a pesquisa qualitativa auxilia nas investigações realizadas na Educação Matemática e nas outras áreas da Educação, pois ao fazer a pesquisa é possível identificar modos que tenham como objetivo, fazer sentido no que se aprende (SCHIRLO e SILVA, 2013).

A metodologia de pesquisa utilizada é descrita pela pesquisa-ação, a qual é interpretativa e faz a união da teoria com a prática por meio de alguma ação que tenha como propósito realizar uma transformação na realidade estabelecida. Assim, essa pesquisa é realizada a partir de um problema coletivo, para o qual os pesquisadores procuram uma solução (KOERICH et al., 2009). A pesquisa-ação é feita por meio de etapas: inicialmente deve-se planejar um aperfeiçoamento da prática, identificando seu problema e levantando dados pertinentes, em seguida deve-se agir para implantar essa mudança, de forma a encontrar possíveis soluções, posteriormente descrever os efeitos dessa ação, a partir da análise dos dados levantados e do significado em melhorar isto, e por fim deve-se avaliar os resultados dessa transformação (KOERICH et al., 2009).

Esses passos descritos anteriormente, mostram como pode ser realizada a pesquisa-ação e, também, como utilizamos a mesma na pesquisa. Sendo assim, descreveremos na próxima seção a atividade realizada e o contexto da pesquisa que tinha por finalidade principal propiciar uma aprendizagem significativa e contextualizada do conteúdo de Funções.

\section{Percurso metodológico: Contexto da Pesquisa e Descrição da Atividade}

Como nossa pesquisa se caracteriza por uma pesquisa-ação, contextualizaremos nosso campo de pesquisa e sujeitos da pesquisa, assim como realizaremos a descrição da atividade que foi realizada pela professora-pesquisadora, primeira autora do artigo. 0 projeto foi aplicado na Escola Estadual de Ensino Médio Cavalheiro Aristides Germani, no município de Caxias de Sul (RS), com seis turmas de $1^{\circ}$ ano. Tem como contexto o desafio que enfrentamos nos tempos atuais, a utilização do celular em sala de aula. Este projeto visa desenvolver uma educação voltada para o futuro, de forma que se utilize o celular como auxílio nas aulas de Matemática.

Na primeira etapa foi proposto o tema central da atividade e desenvolvido um seminário, no qual os estudantes expuseram suas opiniões sobre o tema Celular e seu uso consciente, 
baseado no senso comum, sem pesquisa prévia. 0 objetivo nessa etapa era o de contextualizar 0 assunto, bem como a sondagem dos conhecimentos prévios.

Esse foi um momento de interação e descontração, no qual os estudantes conversaram sobre o tema. Como esperado, focaram na utilização do celular em sala de aula. É importante salientar que a professora somente escreveu o título da temática da aula no quadro, e não direcionou o debate para o uso do celular em sala de aula. Após algum tempo de debate sobre este tema, a professora deixou claro que o assunto era mais amplo e podia ter um aprofundamento maior. Neste momento surgiram questões sobre o uso do celular nas empresas e o modo como afeta a produção nas mesmas, o impacto que ele tem na saúde dos usuários, entre outros.

A seguir, a professora orientou que os estudantes se reunissem em grupos de até cinco integrantes, solicitando que escolhessem um nome para cada equipe, salientando que a atividade de cada grupo deveria ser individual (dentro do grupo), por isso a interação entre os grupos não foi estimulada. 0 objetivo desta instrução foi o de garantir que cada grupo desenvolvesse sua própria linha de pesquisa, garantindo assim a originalidade da produção de cada grupo.

A professora explicitou que essas atividades seriam meramente com foco organizacional, pois todos os integrantes do grupo deveriam participar ativamente das atividades. Foram dadas instruções de funções para cada integrante dentro do grupo, sendo que cada estudante podia assumir somente uma, como estão descritas abaixo:

- Líder: sua função seria delegar funções e organizar a equipe.

- Redator: transcrever para o diário da equipe todas as etapas do desenvolvimento da atividade. Foi salientado que os erros e pesquisas descartadas também deveriam fazer parte do relato.

- Relator: relatar ao fim de cada aula, os progressos do grupo para a professora orientadora.

- Secretário: ajudar o líder nas funções administrativas, como por exemplo, providenciar os materiais necessários para as atividades.

Em seguida foi entregue aos grupos, artigos que abrangeram o conteúdo a ser abordado na aula, ou seja, função polinomial de $1^{\circ}$ grau, para que iniciassem suas pesquisas. Foram disponibilizados, para os estudantes, dois períodos de 50 minutos para que fizessem a leitura dos artigos. No decorrer da aula, foi orientado para que fizessem anotações sobre os aspectos mais importantes. No final das aulas o relator de cada grupo faria um breve relato para a professora 
sobre o texto lido e a opinião do grupo em relação ao assunto. Todos os grupos deveriam ler 0 material, fazendo as devidas observações.

Depois de feitas as anotações, as quais ficaram reservadas para um segundo momento, os alunos se dirigiram para a sala de informática, na qual cada grupo deveria fazer uma pesquisa sobre valores de planos para telefones móveis e valores excedentes ao plano por ligação. A orientação era que fosse realizada uma pesquisa com diferentes operadoras e eles deveriam escolher pelo menos duas diferentes para anotar e fazer uma comparação futura.

No final da pesquisa os estudantes realizaram uma atividade avaliativa, utilizando como base suas pesquisas e conclusões. Durante a realização do trabalho que durou em torno de quatro períodos, a professora interagiu com os grupos e acompanhou a evolução do trabalho, de modo a instigar os estudantes a chegar às suas próprias conclusões.

$\mathrm{Na}$ análise realizada, utilizamos as escritas dos estudantes referentes à atividade desenvolvida, quais foram seus principais pontos, sejam eles negativos e/ou positivos, e se os estudantes haviam gostado da atividade. Essas escritas foram realizadas em grupos, de acordo com a descrição da atividade, contabilizando sete textos analisados dos estudantes.

Com isso, a partir da análise qualitativa das escritas, percebemos duas emergências relacionadas à potencialidade de uma atividade didática contextualizada para o ensino de Matemática com estudantes do Ensino Médio: a primeira relaciona à Matemática com o cotidiano do estudante, e, a segunda, a Matemática como fonte de pesquisa. Nas duas seções seguintes discutimos esses resultados por meio da escrita dos estudantes, dos teóricos que embasam essas emergências e das nossas concepções.

\section{Compreensões dos estudantes em Matemática a partir de questões cotidianas}

A Matemática pouco é relacionada com nosso cotidiano, fazendo com que os estudantes encontrem dificuldades para relacionar o conteúdo ensinado com o seu dia a dia. Sendo assim, por diversas vezes os estudantes acabam se questionando sobre a utilização desse conhecimento. Ao contextualizarmos a Matemática instigamos o estudante em estar aprendendo determinados conteúdos, assim como dando significado aos mesmos (REIS e NEHRING, 2017).

Nessa perspectiva, percebemos com a escrita do Grupo 1 que, muitas vezes, para os estudantes, a Matemática não está presente no seu cotidiano: "Achamos muito bom o trabalho, 
pois ele nos mostra que a Matemática não é só conta, que realmente podemos usá-la em nosso dia a dia" (G1). Ressaltamos com essa escrita, que é infrequente a associação da Matemática com o nosso cotidiano, por diversas vezes o professor é questionado pelos estudantes, sobre como e no que será utilizado o aprendizado daquele conteúdo futuramente. De acordo com Cunha (2017), isso acontece devido a Matemática ser considerada uma ciência difícil pela comunidade escolar, que exige amplo raciocínio em suas questões, o que propicia o distanciamento da sua prática com o cotidiano.

$\mathrm{Na}$ escrita do Grupo 2 também notamos essa dificuldade no conteúdo abordado de Matemática: "Tivemos dificuldades na parte das equações e dos gráficos. Gostamos das pesquisas e de saber como podemos usar a Matemática no dia a dia. O que menos gostamos foi a falta de coerência entre os planos de celulares" (G2). Percebemos com essa escrita que além dos estudantes frisarem a importância de compreender como o conteúdo pode fazer parte do seu contexto, citam ainda a incoerência dos planos de celulares, se tornando críticos do processo e percebendo a existência de propagandas que podem ser enganosas.

Nesse seguimento, consideramos de extrema importância fomentar a criticidade na formação dos sujeitos, pois dessa forma os jovens poderão entender que o pensamento crítico faz parte do processo de ensino e de aprendizagem. No entanto, a potencialidade da formação de um pensamento crítico é potencializada com um ensino contextualizado (BRASIL, 2017).

Observamos que, para o professor, o conhecimento atravesse dá por meio de investigações racionais e lógicas, enquanto para o estudante boa parte do conhecimento produzido é pelos seus afazeres cotidianos. Assim, um dos questionamentos mais presentes no âmbito escolar é: Em que situações cotidianas irei utilizar o presente aprendizado? Com isso, vemos a necessidade de argumentar cuidadosamente com o estudante, esclarecendo suas ideias e investigações, e o auxiliando a entender a importância e a utilidade em se aprender Matemática (LUCCAS e BATISTA, 2008).

Na escrita do grupo 3, notamos novamente a importância da relação da atividade com 0 cotidiano, que apesar de ser algo que demande certo tempo, é vista pelos estudantes como algo útil: "Nós gostamos, pois foi um trabalho diferente que iremos usar futuramente na nossa vida, foi em grupo e fomos à informática. Só não gostamos muito que é um trabalho bem trabalhoso e difícil" (G3). O estímulo de aplicar futuramente algo aprendido no presente, faz com que estudantes desejem esse aprendizado. Assim, aumenta consideravelmente o desempenho deles em sala de 
aula, pois sabe-se que mesmo que futuramente, há uma ligação da Matemática com acontecimentos diários (CUNHA, 2017).

De acordo com pesquisas feitas, a contextualização no ensino e aprendizagem é uma parte do processo de formação de um cidadão crítico. No entanto, percebemos que somente essa estratégia metodológica pode não suscitar o desejo dos estudantes em compreender a Matemática. Com isso, ressaltamos que a realização de pesquisas em sala de aula, também pode ser um fator que propicia um interesse nessa disciplina.

A pesquisa é eficiente em formar novos conceitos de aprendizagem, e quando existe a união com o ensino contextualizado tem potencial em formar o pensamento crítico do estudante (REIS e NEHRING, 2017). Dessa forma, na próxima seção explicitaremos a discussão sobre a pesquisa como potencializadora do ensino e aprendizagem em Matemática.

\section{A pesquisa como potencializadora do ensino e da aprendizagem em Matemática}

Dissertamos, anteriormente, que um ensino contextualizado em Matemática, que apresente relações com fatos cotidianos da vida do estudante, contribuem para a suas compreensões conceituais. Além dessa forma metodológica de conduzir os processos de ensino e de aprendizagem, notamos com a análise realizada que a inserção da pesquisa em sala de aula também potencializa o desenvolvimento de conceitos matemáticos. A pesquisa tem como propósito produzir conhecimento, de maneira com que 0 estudante obtenha respostas a suas perguntas iniciais e potencialize o desenvolvimento de novas perguntas (REIS e NEHRING, 2017).

Diante das escritas dos grupos, foram apresentados por diversas vezes, a relevância da inserção da pesquisa em sala de aula. $O$ grupo 4 fez a seguinte fala em relação a atividade: "No início nossa experiência sobre a atividade foi meio assustadora, porque no começo não entendemos muito, mas depois ao longo das pesquisas fomos compreendendo" (G4). Diante disso, notamos a importância de atividades que envolvam a pesquisa, pois ao pesquisar o sujeito buscará compreensões significativas do seu ponto de vista, sendo que diante a um problema, há a necessidade de encontrar respostas que sejam convenientes e claras (BICUDO, 1993).

De acordo com Castro (2004), a pesquisa é capaz de permitir um olhar diferente sobre a prática e é colaboradora diante os fatores que ocorrem, sem a pesquisa antes da prática corremos o risco de não compreender os fatos ocorridos. Observamos na escrita do Grupo 4, a análise sobre 
os novos aprendizados que constituíram a pesquisa: "Foi uma experiência muito significativa, ficamos sabendo de várias coisas de celulares. O que mais gostamos foi à parte da pesquisa pois descobrimos que não havia benefício nos nossos planos de celulares escolhidos e o que menos gostamos foi de fazer os gráficos" (G5). Ressaltamos, que a pesquisa se mostra como fonte do conhecimento, não podendo ser compreendida como algo utilizado apenas para buscar falhas em algo já feito, mas sim de como preveni-las, logo a pesquisa se torna mais frequente na vida do estudante (CASTRO, 2004).

Compreendemos que o ponto principal durante uma pesquisa é constituído por dúvidas, que se comportam de maneira a instigar o pesquisador, de modo com que ao fim da pesquisa se esclareça as mesmas. 0 grupo 6 escreveu a respeito de como a pesquisa salientou suas dúvidas.

Em um todo a experiência foi muito boa, é interessante e inteligente abordar um assunto tão comentado hoje em dia. Para nós, a pesquisa nos fez entender coisas novas e tirar várias dúvidas que tínhamos a respeito de operadoras de celulares, fez também com que abríssemos os olhos para ver como a mídia tem poder sobre as pessoas. O que mais gostamos foi a escolha do assunto e a quantidade de coisas novas que descobrimos. A parte que menos gostamos foi no início da pesquisa pois não sabíamos por onde começar (G6).

O último grupo também falou a respeito da pesquisa, e na dificuldade que teve para iniciála: "Foi uma experiência nova, que nunca tínhamos feito antes. Achamos interessante, pois foi uma pesquisa diferente, e além da pesquisa você [professora] colocou questões matemáticas. 0 que menos gostamos foi no início da atividade pois estávamos perdidos em como começar" (G7).

Percebemos que para se iniciar uma pesquisa devemos focar nos questionamentos sobre o referido assunto, ou seja, o motivo pelo qual iremos realizar a mesma. Além disso, durante a pesquisa é interessante questionar os estudantes se o caminho que estão seguindo está correto, se estão encontrando respostas para o problema, pois a pesquisa está inteiramente ligada a perseguir perguntas, ir em busca de um sentido para o que se foi perguntado, e há diversas maneiras significativas e convenientes para que a investigação seja bem sucedida (BICUDO, 2012).

A pesquisa aborda questões que buscam se desenvolver durante seu desenvolvimento; muitas vezes as pesquisas são subestimadas no ensino da Matemática, devido a Matemática ser reconhecida apenas por seus números, pouco se dispõe a pesquisa aos estudantes. Sabe-se que o campo de pesquisas provoca novos conhecimentos e quando em união com a prática, é capaz de desencadear o interesse pelos alunos e proporcionar um ensino contextualizado. Apesar de 
existir diversas perspectivas diferentes sobre a pesquisa, todas apresentam o mesmo propósito, o de aprimorar ou ainda aflorar o conhecimento (DUVAL, 2012).

\section{Considerações Finais}

Ao realizar esse trabalho tivemos por objetivo desenvolver uma atividade diferenciada no ensino de Matemática para estudantes do Ensino Médio, os quais pudessem ter a oportunidade de utilizar instrumentos como computador, celular e calculadora, ao trabalhar no ensino de Matemática. Com a utilização do celular, os estudantes compararam planos de operadoras e foi trabalhado o conteúdo de gráficos de funções de primeiro grau. Em relação ao desenvolvimento da atividade, em que foi realizada uma análise reflexiva da prática em sala de aula, percebemos que os estudantes compreendem que atualmente o celular é visto como um problema no ensino, e que seu uso em sala de aula poderia ser melhor adequado, ao invés de proibido. Discutindo sobre esse tema, proposto pelos estudantes, explicitamos que boa parte da dificuldade que eles apresentam no ensino de Matemática está ligada à dificuldade de relacionar a Matemática com acontecimentos do dia a dia, e foi visto, durante a atividade, a dificuldade que eles enfrentaram ao realizar pesquisas, isto acontece devido a ser algo pouco proposto aos estudantes nas aulas de Matemática.

Dessa forma, ressaltamos a importância de relacionarmos os conceitos matemáticos com fatos cotidianos, além de levarmos a pesquisa para sala de aula. Essas estratégias metodológicas, em conjunto com a temática do uso do celular, possibilitaram que os estudantes se envolvessem na aula e os instigassem a buscar compreender fatos além dos conceitos postos.

Com isso, percebemos que uma aula de Matemática que abranja outras formas de ensinar e de aprender, pode possibilitar uma ampliação na visão dos estudantes diante o motivo de ter que aprender determinados conteúdos. Argumentamos, dessa forma, que ao realizar uma prática contextualizada e investigativa potencializamos o processo de formação de sujeitos conscientes e críticos.

\section{Referências}

ALBINO, Thais Senna de Lanna. A prática docente e o uso de metodologias alternativas no ensino de Matemática: um olhar para as escolas que adotam propostas pedagógicas diferenciadas. In: ENCONTRO BRASILEIRO DE ESTUDANTES DE PÓS-GRADUAÇÃO EM EDUCAÇÃO 
MATEMÁTICA, 19, 2015, Juiz de Fora. Anais do XIX EBRAPEM. Juiz de Fora: UFJF, 2015, p. 1 12.

BECKER, Fernando. Modelos pedagógicos e modelos epistemológicos. In: SILVA, Luiz Heron da; AZEVEDO, José Clovis de. (Org.). Paixão de aprender II. Petrópolis: Vozes, 1995, p. 18-23.

BICUDO, Maria Aparecida Viggiani. Pesquisa em Educação Matemática. Pro-Posições, Campinas, v. 4, n. 1, p. 18-23, mar. 1993.

BICUDO, Maria Aparecida Viggiani. A pesquisa em Educação Matemática: a prevalência da abordagem qualitativa. Revista Brasileira de Ensino de Ciência e Tecnologia, Ponta Grossa, v. 5, n. 2, p. 15-26, maio/ago. 2012.

BRASIL. Ministério da Educação. Secretaria de Educação Básica. Base Nacional Comum Curricular. Educação Infantil e Ensino Fundamental. Brasília: MEC/SEB, 2017.

BRASIL. Ministério da Educação. Secretaria de Educação Fundamental. Parâmetros Curriculares Nacionais: Terceiro e Quarto Ciclos do Ensino Fundamental — Matemática. Brasília: MEC/SEF, 1998.

BUENO, Simone; ALENCAR, Edvonete Souza de; MILLONES, Teresa Sofia Oviedo. Reflexões e desafios da resolução de problemas nas aulas de Matemática: um ensaio teórico. Educação Matemática Debate, Montes Claros, v. 1, n. 1, p. 9-27, jan./abr. 2017.

CASTRO, Juliana Facanali. Um estudo sobre a própria prática em um contexto de aulas investigativas de Matemática. 2004. 197f. Dissertação (Mestrado em Educação) — Faculdade de Educação. Universidade Estadual de Campinas. Campinas.

CUNHA, Cézar Pessoa. Importância da Matemática no cotidiano. Núcleo do Conhecimento, v.1, n. 2, p. 641-650, jul. 2017.

DUVAL, Raymond. Quais teorias e métodos para a pesquisa sobre o ensino da Matemática? Práxis Educativa, Ponta Grossa, v. 7, n. 2, p. 305-330, jul./dez. 2012.

KOERICH, Magda Santos; BACKES, Dirce Stein; SOUSA, Francisca Georgina Macêdo de; ERDMANN, Alacoque Lorenzini; ALBURQUERQUE, Gelson Luiz. Pesquisa-ação: ferramenta metodológica para a pesquisa qualitativa. Revista Eletrônica de Enfermagem, Goiânia, v. 11, n. 3, p. 717-723, 2009.

LESSA, Mônica Maria Lins; FALCÃO, Jorge Tarcisio da Rocha. Pensamento e Linguagem: uma discussão no campo da Psicologia da Educação Matemática. Psicologia: Reflexão e Crítica, v. 18, n. 3, p. 315-322, set./dez. 2005.

LUCCAS, Simone; BATISTA, Irinéa de Lourdes. A importância da contextualização e da descontextualização no ensino de Matemática: uma análise epistemológica. In: ENCONTRO BRASILEIRO DE ESTUDANTES DE PÓS-GRADUAÇÃO EM EDUCAÇÃ̃O MATEMÁTICA, 2, 2008, Rio Claro. Anais do II EBRAPEM. Rio Claro: UNESP, 2008, p. 1-17.

MAIOLI, Márcia. A contextualização na Matemática no Ensino Médio. 2012. 210f. Tese (Doutorado em Educação Matemática) — Faculdade de Ciências Exatas e Tecnologias. Pontifícia 
Universidade Católica de São Paulo. São Paulo.

MARTINS, Carla Macedo. Vigotski e o "aprender a aprender": críticas às apropriações neoliberais e pós-modernas da teoria vigotskiana. Trabalho, Educação e Saúde, Rio de Janeiro, v.1, n. 1, p. 166-171, mar. 2003.

NOGUEIRA NETO, Euclides. A contextualização no ensino da Matemática. 68f. 2019. Dissertação (Mestrado Profissional em Matemática em Rede Nacional) - Centro de Ciências Exatas e Naturais. Universidade Federal Rural do Semi-Árido. Mossoró.

PELIZZARI, Adriana; KRIEGL, Maria de Lurdes; BARON, Márcia Pirib; FINCK, Neley Terezinha Lubi; DOROCINSKI, Solange Inês. A Teoria da Aprendizagem Significativa segundo Ausubel. Psicologia Educação e Cultura, Curitiba, v.2, n. 1, p. 37-42, jul. 2002.

PINTO, Antonio Henrique. A Base Nacional Comum Curricular e o ensino de Matemática: flexibilização ou engessamento do currículo escolar. Bolema, Rio Claro, v.31, n. 59, p. 1045-1060, dez. 2017.

PONTES NETO, José Augusto da Silva. Teoria da aprendizagem significativa de David Ausubel: perguntas e respostas. Série-Estudos, Brasília, n. 21, p. 117-130, jan.jun. 2006.

REIS, Ana Queli; NEHRING, Cátia Maria. A contextualização no ensino de Matemática: concepções e práticas. Educação Matemática Pesquisa, São Paulo, v. 19, n. 2, p. 339-364, 2017.

SCHIRLO, Ana Cristina; SILVA, Sani de Carvalho Rutz da. A pesquisa qualitativa na Educação Matemática: um diálogo auxiliando a formação do professor/pesquisador. Espacios, v. 34, n. 12, p. 16, 2013.

SOUZA, Jaibis Freitas de. Construindo uma aprendizagem significativa com história e contextualização da Matemática. 2009. 108f. Dissertação (Mestrado em Educação Agrícola) Instituto de Agronomia. Universidade Federal Rural do Rio de Janeiro. Seropédica.

SOUZA, João Bosco de Souza. Uma análise sobre contextualização matemática. 2019. $120 f$. Dissertação (Mestrado em Profissional em Matemática em Rede Nacional) - Centro de Ciências e Tecnologia. Universidade Federal de Campina Grande. Campina Grande.

TUFANO, Wagner. Contextualização. In: FAZENDA, Ivani. (Org.). Dicionário em construção: Interdisciplinaridade. 2 ed. São Paulo: Cortez, 2002, p. 40-45. 